\title{
Pattern of Complementary Feeding among Mothers Having Child Aged 6 to 12 Months
}

\author{
Md Monoarul Haque ${ }^{1}$, Nurun Nahar ${ }^{2}$, Md Shafiullah Prodhania ${ }^{3}$ \\ Farzana Rahman Lima ${ }^{4}$, Md Rijwan Bhuiyan ${ }^{5}$, S. M. Azmol Hossain ${ }^{6}$
}

\begin{abstract}
Background: Infant feeding practices play a crucial role in determining a child's rate of growth and development. Improper feeding practices have not only continued to jeopardize the nutritional status of Bangladeshi Children but also the well being of millions of children all over the world. Objective: The aim of the study was to assess pattern of complementary feeding among mothers having child aged 6 to 12 months. Materials and method: This was a cross sectional study conducted among 125 mothers having child aged 6 to 12 months. Purposive sampling method was used and pretested structured questionnaire was used to collect data by face to face interview. Prior data collection verbal consent was taken from respondents. Results: Mean age of the infants was $9.95 \pm 2.046$ months. Maximum 24\% of the mothers were educated up to class VI-IX. About $47.2 \%$ mother introduced complementary feeding at $6^{\text {th }}$ month to their infants. Among the age group of 6 to 8 months 13.9\%, 44.4\%, 30.6\% and $11.1 \%$ children received meal for 1-2 times/day, 3-4 times/day, 5-6 times/day and more than 6 times/day respectively. In 6-8 months age group 52.8\%, 19.4\%, 16.7\%, 8.3\% and $2.8 \%$ were given semi solid and liquid, semi solid and solid, liquid, semi solid, and solid respectively. Besides 64\% respondents gave 'Rice/Rice Powder/Suzy' as complementary feeding, $60 \%$ received 'khichuri', and $4.85 \%$ gave non-infant formulae. Conclusion: Overall pattern of complementary feeding was not satisfactory. Further large scale study is needed to get actual picture.
\end{abstract}

Keywords: Pattern; complementary feeding; 6 to 12 months aged child.

Delta Med Col J. Jan 2016;4(1):13-17

\section{Introduction}

Growth of all Infants from the age of six months onwards depends largely upon the provision of additional building materials supplied through complementary foods in order to help them grow into healthy and active adults. They need to be fed on a diet that provides all the nutrients and energy required for normal growth; vitamins and minerals to alleviate their hidden hunger and keep them

1. Fellow, Faculty of Public Health, Bangladesh University of Health Sciences (BUHS), Dhaka, Bangladesh.

2. Master of Public Health, ASA University of Bangladesh, Dhaka, Bangladesh.

3. Assistant Professor, Bangladesh Medical College, Dhaka, Bangladesh.

4. Assistant Professor, National College of Home Economics, Dhaka, Bangladesh.

5. MPhil in Public Health, Bangladesh Institute of Health Sciences (BUHS), Dhaka, Bangladesh.

6. Masters in Public Health, ASA University of Bangladesh, Dhaka, Bangladesh.

Correspondence: Monoarul Haque. e-mail: monoarmunna@yahoo.com 
strong. ${ }^{1}$ Complementary feeding has been defined as the provision of nutrient containing foods or liquids other than breast milk that includes both solid foods and infant formula. ${ }^{2}$ This refers to the period during which an infant becomes accustomed to complementary foods or infant formula in addition to the routine breast milk. The amount, type and consistency of food depend on the age of the child. This is also called 'intermediately period'. In developing countries, it covers a period between four months to two years, when the incidence of malnutrition and deficiency disease is at highest. ${ }^{3}$ WHO recommends that infants start receiving complementary foods at 6 months of age in addition to breast milk, initially 2-3 times a day between 6-8 months, increasing to 3-4 times daily between 9-11 months and 12-24 months with additional nutritious snacks offered 1-2 times per day. ${ }^{4}$ Infant feeding practices play a crucial role in determining a child's rate of growth and development. A point of great concern among nutritionists and the professionals is that improper feeding practices have not only continued to jeopardize the nutritional status of Bangladeshi children but also the well being of millions of children all over the world. Introduction of timely, adequate and balanced complementary food is perhaps the most important single and direct remedial measure to combat infants' malnutrition. The education of the mother is also considered to have a great impact on infants' nutritional status. The more a mother is knowledgeable the more she shall be able to help her child to grow nutritionally healthy as a young adult. ${ }^{5}$ There were not enough studies on pattern on complementary feeding in our country. This study will be helpful to provide new information to the mothers and will help to make them aware about complementary feeding practice and help the policy makers to run a successful program.

\section{Materials and method}

Study design: This was a cross-sectional study conducted in a slum area of Mirpur, Dhaka, Bangladesh from June to September 2012.
Study population: Mothers who have infant aged between 6 to 12 months.

Sample size and sampling technique: A total of 125 samples were selected purposively to conduct this study.

Data collection tools and technique: Data were collected through face to face interview by using pre-tested structured questionnaire.

Ethical issue: Verbal informed consent was taken from positive respondents with maintaining their full autonomy.

Data processing and analysis: Collected data were checked and completed in a master sheet. Data were then analyzed by using SPSS version 17.0. Standard general statistical method was applied using computer for data analysis.

\section{Results}

Mean age of the infants was $9.95 \pm 2.046$ months and most of the infants (51\%) were in 11-12 months age group (Table I).

Table I: Age distribution of the respondents $(\mathrm{N}=\mathbf{1 2 5})$

\begin{tabular}{lcc}
\hline Age of infant (months) & Male & Female \\
\hline $6-8(\mathrm{n}=36)$ & $19(15.2 \%)$ & $17(13.6 \%)$ \\
$9-10(\mathrm{n}=25)$ & $15(12.0 \%)$ & $10(8.0 \%)$ \\
$11-12(64)$ & $33(26.4 \%)$ & $31(24.8 \%)$ \\
Mean \pm SD & \multicolumn{2}{c}{$9.95 \pm 2.046$} \\
\hline
\end{tabular}

Socio-demographic characteristics of the respondents

About $24.8 \%$ of the respondents were educated up to class VI-IX, $12.8 \%$ were educated above graduate and only $7.2 \%$ were graduate. A large proportion $(85.6 \%)$ of the respondents was housewives and $8 \%$ were private service holder. The highest proportion (48.8\%) of families had 3 to 4 members and the lowest proportion $(5.6 \%)$ of families had 9 and more family members. Majority (41.6\%) of the families earned TK 10000-20000 and only $10.4 \%$ of families earned TK 20001-30000 per month (Table II). 
Table II: Socio-demographic characteristics $(\mathrm{N}=125)$

\begin{tabular}{lcc}
\hline Variables & Frequency & Percent \\
\hline Education & & \\
Illiterate & 10 & 8 \\
Class I-V & 18 & 14.4 \\
Class VI-IX & 31 & 24.8 \\
SSC & 23 & 18.4 \\
HSC & 18 & 14.4 \\
Graduate & 9 & 7.2 \\
Above graduate & 16 & 12.8 \\
Occupation & & \\
Housewife & 107 & 85.6 \\
Govt. Service & 4 & 3.2 \\
Private Service & 10 & 8 \\
Others & 4 & 3.2 \\
Family member & & \\
3-4 & 61 & 48.8 \\
5-6 & 45 & 36 \\
$7-8$ & 12 & 9.6 \\
9 and more & 7 & 5.6 \\
Family income (BDT) & & \\
$0-10000$ & 42 & 33.6 \\
$10001-20000$ & 52 & 41.6 \\
$20001-30000$ & 13 & 10.4 \\
$>30000$ & 18 & 14.4 \\
\hline
\end{tabular}

\section{Pattern of complementary feeding}

Maximum respondents (47.2\%) introduced complementary feeding at 6 month to their infants. On the other hand $28.8 \%$ respondents introduced feeding before $6^{\text {th }}$ months, $22.4 \%$ introduced complementary feeding at 7 to 8 months and $1.6 \%$ introduced after 8 months of age of their infants. Among the age group of 6 to 8 months, majority of the infants (44.4\%) received meal 3-4 times/day, $30.6 \%$ received 5-6 times/day and few infants received either only 1-2 times/day or more than 6 times/day. Among the age group 9-11 months, most of the infants $(52.0 \%)$ received meal 5-6 times/day which was $46.9 \%$ among the age group of 11-12 months. Infants of 6-8 months age group were mostly $(52.8 \%)$ given semi solid and liquid, which was 32\% in 9-10 months age group and $31.3 \%$ in 11 to 12 months age group. Most of the (64\%) infants had 'Rice/Rice Powder/Suzy' as complementary feeding, $60 \%$ received khichuri, $44.0 \%$ received pulse, $36.0 \%$ had vegetables, $32 \%$ had egg in meal and the least, $4.85 \%$ had non-infant formula milk. For most of the infants (59.2\%) meal had been prepared separately, $13.6 \%$ had family food and $27.2 \%$ infants had both.
Table III: Pattern of complementary feeding $(\mathrm{N}=\mathbf{1 2 5})$

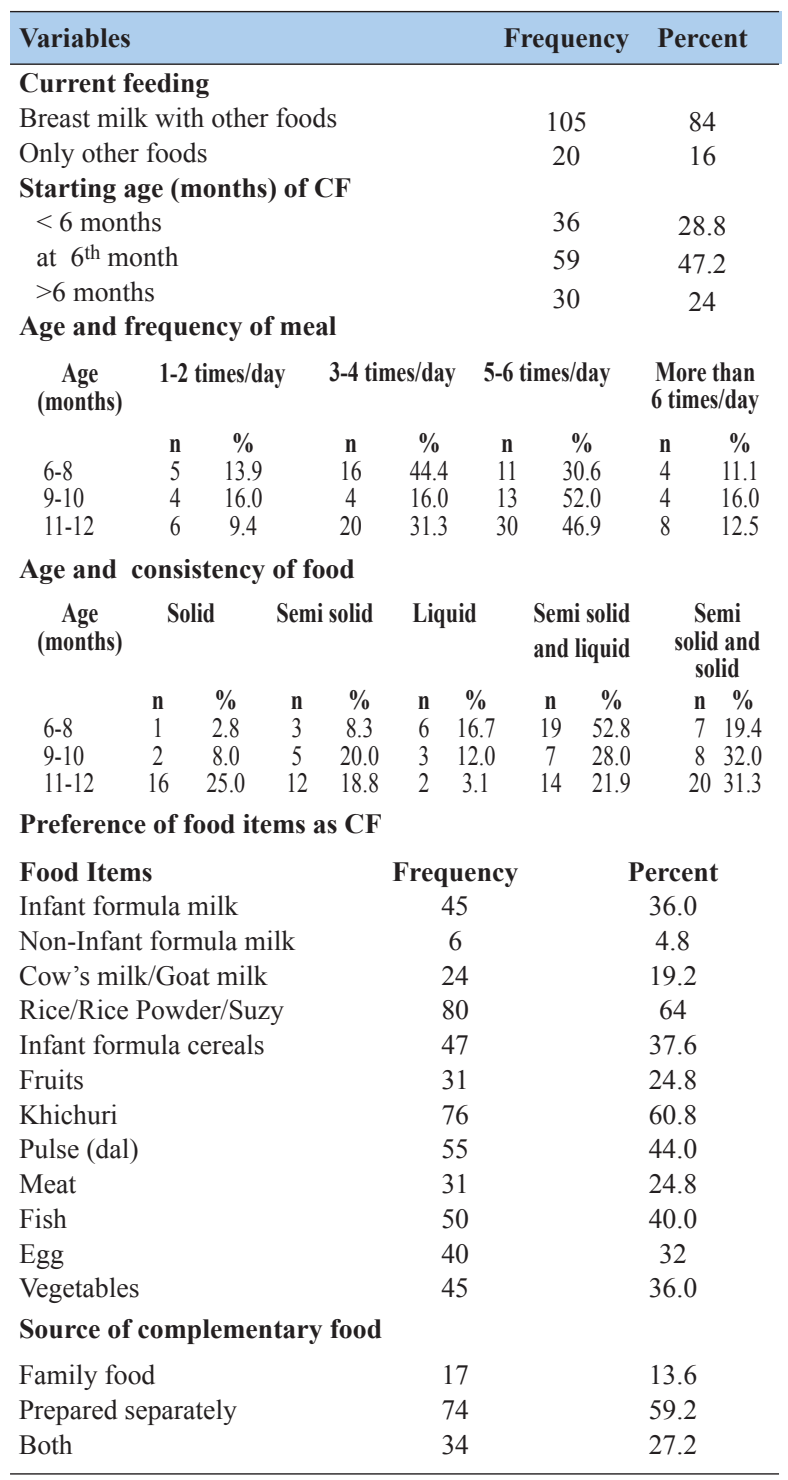

\section{Discussion}

Infants are the vulnerable group in our population. In this study maximum respondents (85\%) were giving breast milk along with other foods to their infants whereas $16 \%$ found to give only other foods. About $47.2 \%$ of the mothers started complementary feeding to their infants at 6 months and the percentage of too early start and delayed introduction of complementary feeding was $28.8 \%$ and $24 \%$ respectively. A study addressing the nutritional status in a National Nutrition Programme in Bangladesh showed that timely 
complementary feeding was given to $83 \%$ of infants and $16.9 \%$ of mothers started complementary feeding at an early age. ${ }^{6}$ In the present study the early starting of complementary feeding rate was $28.8 \%$. A study done several years back by Aggarwal et al. ${ }^{7}$ showed that only $17.5 \%$ of mothers had started complementary feeding at the recommended time which might reflect the fact that by this time awareness about complementary feeding has improved much.

A study of complementary feeding practices among mothers of some selected slums of Dhaka city done by Saleh et al. ${ }^{8}$ reported that in 9-11 months of age group about $70 \%$ mothers gave complementary foods twice a day to their children which was $16 \%$ in this study and $52 \%$ infants had meal 5-6 times/day. The frequency of complementary feeding was 3 times a day in $56 \%$ of the infants at 12-23 months of age. ${ }^{8}$ In our study, among the age group of 11-12 months $31.3 \%$ received meal 3-4 times/day.

In this study the most preferred (64.8\%) food item given by the mothers was 'Rice/Rice powder/Suzy' and 'khichuri' was the second most common food which they gave along with pulse (44.0\%), fish (40\%), vegetables (36\%), egg (32\%), and meat (24\%). The National Nutrition Programme also reported that consumption of rice and 'khichuri' was higher compared to meat, fish, and egg. ${ }^{6}$ Only $36 \%$ infants received infant formula in this study whereas a study among rural infants found it to be $72.7 \% .^{9}$

Most of the mothers prepared infant's food separately and only $13.6 \%$ practiced giving family food as per WHO recommendation. ${ }^{10} \mathrm{~A}$ large number of mothers (84\%) were continuing breast milk along with other foods to their infants as per WHO recommendation ${ }^{10}$, the percentage is higher (93\%) in the National Nutrition Programme. ${ }^{6}$

\section{Conclusion}

After the period of exclusive breastfeeding, the diet undergoes a change, from a single food breast milk, to a variety of complementary foods plus breast milk, to meet infants' nutritional requirements. This period is associated not only with increasing and changing nutrient requirements, but also with rapid growth, physiological maturation and development of the infant. Poor nutrition during this critical period of life may increase the risk of growth faltering and micronutrient deficiencies, and may have adverse effects on health and mental development. The prevalence of under nutrition among infants rises sharply between 6 and 11 months of age, providing stark evidence of poor complementary feeding. The complementary meals given to infants aged 6 to 11 months old rarely contain commonly eaten Bangladeshi foods which are rich in micronutrients and protein, such as fish, pulse and eggs and vegetables. As this study is done in a selected slum area of Dhaka, it might not be the representative picture of the complementary feeding pattern of Bangladesh in general. So further large scale study including representative samples should be carried out to get the real picture and future action plan.

\section{References}

1. Liaqat P, Rizvi MA, Qayyum A, Ahmed H, Ishtiaq N. Maternal Education and Complementary Feeding. Pakistan Journal of Nutrition. 2006;5(6):563-68.

2. Foote KD, Marriott LD. Weaning of infants. Arch Dis Child. 2003;88(6):488-92.

3. Iliyas MA. Preventive Paediatrics. In: Community Medicine. $3^{\text {rd }}$ ed. Urdu Bazar Karachi: Time Traders; 1993.p.176-77.

4. World Health Organization [Internet]. Strengthening Action to Improve Feeding of Infant and Young Children 6-23 Months of Age in Nutrition and Child Health Programme; 2008 Oct 6-9; Geneva (cited 2012 July 17). Available from: http://apps. who.int/iris/bitstream/10665/44034/1/97892415978 90_eng.pdf.

5. Smith LC, Haddad L. Explaining Child Malnutrition in Developing Countries: A Cross Country Analysis. Washington DC: International Food Policy Research Institute; 1999 April. Research Report 111. 
6. Sultana S, Hoque A, Saleh F. Infant and Young Child-feeding Practices and Their Nutritional Status in a National Nutrition Programme Area in Bangladesh: A Cross-Sectional Study. J Hum Nutr Food Sci. 2014;2(2):1028.

7. Aggarwal A, Verma S, Faridi M, Dayachand. Complementary Feeding - Reasons for Inappropriateness in Timing, Quantity and Consistency. Indian J Pediatr. 2008;75(1):49-53.

8. Saleh F, Ara F, Hoque MA, Alam MS. Complementary Feeding Practices among Mothers in Selected Slums of Dhaka City: A Descriptive Study. J Health Popul Nutr. 2014;32(1):89-96.
9. Gupta RD. Feeding Practices among Infants in a Rural Community in Bangladesh: A Cross-Sectional Study. IJMS. 2014;2(3). Available from: http://www.ijms.info/ojs/index.php/IJMS/article/vie w/127\#.VmFw_1LxLIU.

10. World Health Organization [Internet]. Guiding Principles for Complementary Feeding of the Breastfed Child. 2002 (cited 2012 July 19). Available from: http://www.who.int/nutrition/ publications/guiding_principles_compfeeding_brea stfed.pdf. 